\title{
Kritička informacijska pismenost u akademskom kontekstu
}

\author{
Sonja Špiranec \\ Sveučilište u Zagrebu \\ Filozofski fakultet - Odsjek za informacijske i komunikacijske znanosti, Zagreb, Hrvatska \\ sspiran@ffzg.hr
}

\section{Sažetak}

Unatoč tomu što se informacijska pismenost danas neprijeporno može smatrati konsolidiranim teorijskim konceptom i prepoznatim praktičnim područjem djelovanja u knjižničarstvu, mnoge inicijalne postavke informacijske pismenosti danas se dovode u pitanje. Brojna preispitivanja i kritike koncepta, njegove svrhe i praktičkih manifestacija rezultirale su zaokretom prema kritičkoj informacijskoj pismenosti.

Cilj je ovoga rada utvrditi pruža li kritička informacijska pismenost jedinstven teorijski doprinos u suvremenim promišljanjima o informacijskoj pismenosti. U tu svrhu će se primjenom kvalitativnog pristupa analize literature ispitati osnovne ideje $i$ konceptualna polazišta kritičke informacijske pismenosti te kontrastirati prevladavajući instrumentalno-operativni vid tumačenja informacijske pismenosti s kritičkim pristupima. Pritom će se pokušati utvrditi koliko koncepti kritičke informacijske pismenosti reflektiraju pitanja, dileme i probleme koji su u posljednjih nekoliko desetljeća ustanovljeni u teoriji i praksi informacijskog opismenjivanja i pružaju li zadovoljavajuće uporište za uočene nedostatke, s posebnim osvrtom na visokoškolski kontekst.

Ključne riječi: kritička informacijska pismenost, visoko obrazovanje, standardi, Okvir za informacijsku pismenost u visokom obrazovanju, teorijsko utemeljenje, tržište rada, pristup usmjeren na vještine

\section{Uvod}

Pojam informacijske pismenosti u kontekstu visokog obrazovanja donekle je konsolidiran u značenju te je u usporedbi s drugim sredinama (npr. primarno ili sekundarno obrazovanje) upravo u tercijarnom obrazovanju doživio svoj najveći procvat, kako u izvedbenom smislu kroz formalnu integraciju u nastavne programe, tako i na normativnoj razini uključivanjem u strateške dokumente i politike ${ }^{1}$ ili objavljivanjem standarda koji su omogućili mjerljivost informacijske pismenosti. ${ }^{2}$ No prije tog statusa, informacijska je pismenost prolazila dugi proces konsolidacije i promjene u percepciji na teorijskoj i praktičnoj razini, osobito tijekom 90 -ih i u prvoj polovici 2000-ih godina, ${ }^{3}$ dok se sredinom 2000 -ih dolazi do zaključka da postoji konvergencija u definicijama informacijske pismenosti ${ }^{4}$ koje u svojoj suštini i najmanjem zajedničkom nazivniku obuhvaćaju sposobnosti pristupa, vrednovanja i korištenja informacija. Unatoč pojmovnom konsenzusu, rasprave o smislu, svrsi i praktičnim manifestacijama informacijske pismenosti ne jenjavaju.

1 Usp. UNESCO, Alexandria Proclamation on Information Literacy and Lifelong Learning, http://www.unesco.org/new/en/communicationand-information/resources/news-and-in-focus-articles/all-news/news/alexandria_proclamation_on_information_literacy_and_lifelong/. (preuzeto 22. 2. 2018); American Library Association, Presidential Committee on Information Literacy: Final Report, http://www.ala. org/acrl/publications/whitepapers/presidential. (preuzeto 22. 2. 2018).

2 Association of College, Research Libraries and American Library Association, Information literacy competency standards for higher education (2000), https://alair.ala.org/bitstream/handle/11213/7668/ACRL\%20Information\%20Literacy\%20Competency\%20Standards\%20for\%20Higher\%20Education.pdf?sequence=1\&isAllowed=y (preuzeto 22. 2. 2018)

${ }^{3}$ Jeremy Shapiro i Shelley K. Hughes, "Information literacy as a liberal art?", Educom review 31 (1996): 31-35; Loanne Snavely i Natasha Cooper, "The information literacy debate", The Journal of Academic Librarianship 23, no. 1 (1997): 9-14; James W. Marcum, "Rethinking information literacy" The Library Quarterly 72, no. 1 (2002): 1-26.

${ }^{4}$ Edward K. Owusu-Ansah, "Debating definitions of information literacy: enough is enough!", Library Review 54, no. 6 (2005): $366-374$. 
Te su rasprave često kritički intonirane, pri čemu se inicijalne postavke informacijske pismenosti, kao što su: usmjerenost na vještine i instrumentalni pristup, neutralnost, usmjerenost na zahtjeve tržišta rada i sama standardizacija u području informacijske pismenosti dovode u pitanje, a kao zaokret u promišljanju se nudi skup novih definicija, pristupa, koncepata i okvira koji su u znanstvenom i stručnom diskursu prepoznatljivi kao kritična informacijska pismenost.

Cilj je ovoga rada analizirati ideju i konceptualna polazišta kritičke informacijske pismenosti, dati pregled argumentacije vodećih mislilaca koji se zalažu za zaokret prema kritičkoj informacijskoj pismenosti te suprotstaviti i usporediti prevladavajući instrumentalno-operativni vid tumačenja informacijske pismenosti s kritičkim pristupima. Pritom će se pokušati utvrditi koliko koncepti kritičke informacijske pismenosti reflektiraju pitanja, dileme i probleme koji su u posljednjih nekoliko desetljeća ustanovljeni u teoriji i praksi informacijskog opismenjivanja i pružaju li zadovoljavajuće uporište za uočene nedostatke, s posebnim osvrtom na visokoškolski kontekst.

\section{Put od funkcionalnog prema kritičkom poimanju informacijske pismenosti}

U svrhu razumijevanja potrebe za zaokretom prema kritičkoj informacijskoj pismenosti, potrebno je razumjeti i razmotriti obilježja klasičnog poimanja informacijske pismenosti koja su različiti autori u posljednja dva desetljeća izlagali kritikama. Analizu valja započeti od prve poznatije definicije pojma iz 1974. godine, koja informacijsku pismenost opisuje kao sposobnost korištenja informacijskih izvora i alata na radnom mjestu. ${ }^{5}$ No, upravo se ova definicija, koja se redovito uzima kao početna točka razvoja koncepta, danas kritizira zbog redukcije informacijske pismenosti na postizanje ekonomske kompetitivnosti radne snage i gospodarski uspjeh (američke) industrije. ${ }^{6}$ Takav je diskurs baziran na jeziku produktivnosti i učinkovitosti ${ }^{7}$ te se svodi na instrumentalnu koncepciju generiranja "ljudskog kapitala", koji će, stjecanjem odgovarajućih informacijskih kompetencija, biti u stanju generirati ekonomski rast. ${ }^{8}$ Neki autori dodatno naglašavaju problematičnost povezivanja informacijske pismenosti s idejama neoliberalizma te preporučuju da bi informacijsku pismenost trebalo teorijski preoblikovati kako bi se suprotstavila neoliberalnoj agendi, umjesto da bude utemeljena na njoj. ${ }^{9}$ Već iz ove rasprave razvidno je da su mnogi autori smatrali da su već prva definicija i obrazloženje potrebe za informacijskom pismenošću bili problematični, pri čemu su upućivali na potrebu drugačijeg poimanja.

Drugi ključni moment u povijesti informacijske pismenosti objavljivanje je jednog od najcitiranijih Proglasa ${ }^{10}$ čiji je autor Američko knjižničarsko društvo (American Library Association ALA), koji dokazuje da je bibliotekarska zajednica usvojila informacijsku pismenost kao područje djelovanja struke. $U$ tom se Proglasu informacijska pismenost definira kao skup vještina (npr. vještina pretraživanja, organizacije ili korištenja informacija), koji se potom u daljnjim dokumentima i standardima ove i drugih stručnih organizacija pobliže definira preciznim popisima kompetencija i atributa koji određuju informacijski pismenu osobu. Daleko najutjecajnijim standardom koji je preveden na nekolicinu jezika smatra se američki Information Literacy Competency Standards

\footnotetext{
${ }_{5}^{5}$ Paul G. Zurkowski, The Information Service Environment Relationships and Priorities, Related Paper No. 5 (Washington D.C: National Commission on Libraries and Information Science, 1974), https://eric.ed.gov/?id=ED100391 (preuzeto 27. 2. 2018).

${ }^{6}$ Andrew Whitworth, Radical information literacy: Reclaiming the political heart of the IL movement (Oxford: Chandos, 2014$), 30$.

${ }^{7}$ James Elmborg, "Critical information literacy: Definitions and challenges", Transforming information literacy programs: Intersecting frontiers of self, library culture, and campus community 64 (2012): 75-80.

${ }^{8}$ Cushla Kapitzke, "Information literacy: A positivist epistemology and a politics of outformation", Educational theory 53, no. 1 (2003): 37-53.

${ }^{9}$ Maura Seale, "The neoliberal library", in Information literacy and social justice: Radical professional praxis, Lua Gregory and Shana Higgins, eds. (Sacramento: Library Juice Press, 2013), 58.

${ }^{10}$ American Library Association, Presidential Committee on Information Literacy: Final Report.
} 
for Higher Education ${ }^{11}$ ACRL-a (Association of College and Research Libraries). Njihov cilj je osigurati mjerljivost i vrednovanje pojedinih atributa informacijski pismene osobe kako bi se sam koncept što lakše mogao integrirati u formalni obrazovni sustav.

No, protivnika standardizacije u području informacijske pismenosti nije malo, a među prvima su standarde kritizirali autori Webber i Johnston. ${ }^{12}$ Prema njima je standardizacija kontraproduktivna jer previše pojednostavljuje složeni proces reducirajući ga na jednostavnije i mjerljive vještine, zapostavljajući složenije kompetencije i misaone vještine višeg reda koje se razvijaju informacijskim opismenjivanjem, poput kritičkog mišljenja, tumačenja informacija, vrednovanja i etike korištenja. U standardima se informacijska pismenost svodi na sredstvo postizanja specifične, instumentalno definirane svrhe, a dublje razumijevanje problema ostaje upitno.

Lupton i Bruce ${ }^{13}$ drže da je u standardima informacijska pismenost svedena na vještine. Ove dvije autorice informacijsku pismenost, i sve pismenosti općenito, kategoriziraju kao: 1. funkcionalne, 2. situativne/kontekstualne i 3. kritičke. Drže da u visokom obrazovanju prevladava funkcionalističko-instrumentalni pristup utemeljen i promoviran kroz standarde. Situativni pristup naglašava ulogu informacija u specifičnom kontekstu (npr. disciplina, područje znanosti ili profesionalno okruženje), dok se kritički pristup odnosi na osnaživanje studenata za društvenu promjenu, a ovaj pristup postaje sve popularniji u visokoškolskom knjižničarstvu, osobito među akademskim knjižničarima. No, iako puno knjižničara afirmativno raspravlja o ideji kritičke informacijske pismenosti, ${ }^{14}$ ideje se toliko ne pretaču u svakodnevnu praksu visokoškolskih knjižničara.

Zašto funkcionalni pristup prevladava u praksi akademskih knjižničara, a kritički je još uvijek u povojima i funkcionira samo "na papiru“, donekle je razumljivo. Prema C. Maybee ${ }^{15}$ programi informacijske pismenosti fokusirani na informacijske vještine lakše se poravnavaju s uspostavljenim strukturama u visokom obrazovanju, integriraju u planove i programe itd. Maybee drži da je lakše argumentirati i predočiti menadžmentu u visokom obrazovanju da je informacijska pismenost generička vještina koja je važna za tranziciju u svijet i tržište rada, što u zadnje vrijeme postaje primarna svrha visokog obrazovanja.

Zanimljiv kritički pogled na standarde koji počivaju na funkcionalnom poimanju ponudila je O'Connor, koja se pita jesu li fakultetski knjižničari prigrlili informacijsku pismenost kao sredstvo profesionalne legitimacije, tj. način prevladavanja pomoćnog statusa knjižničara u akademskoj sredini, osobito u uvjetima u kojima su nove tehnologije status knjižničara počele dovoditi u pitanje, pa se informacijska pismenost čini kao konkretan okvir koji omogućuje povećati vidljivost knjižničara na fakultetima i sudjelovanje u nastavnom procesu. ${ }^{16}$

Analiza promišljanja navedenih autora navodi na zaključak da mnogi zagovaraju koncepciju informacijske pismenosti koja se bitno razlikuje od pristupa koji su po svojoj prirodi funkcionalno usmjereni na vještine te dovode u pitanje vrijednosno neutralnu percepciju informacija i kompetencije čija je svrha generirati ekonomski rast. Kao alternativa nameće se kritička informacijska pismenost koja je usmjerena na emancipaciju pojedinca i vodi računa o političkom i društvenom miljeu u kojem se informacije i znanje stvaraju. Ključna obilježja kritičke informacijske pismenosti bit će pobliže prikazani u sljedećem poglavlju.

\footnotetext{
${ }^{11}$ Association of College, Research Libraries and American Library Association, Information literacy competency standards for higher education.

12 Sheila Webber i Bill Johnston, "Conceptions of information literacy: new perspectives and implications", Journal of information science, 26, no. 6 (2000): 381-397.

${ }^{13}$ Mandy Lupton i Christine Bruce, "Windows on information literacy worlds: Generic, situated and transformative perspectives", in Practising information literacy: Bringing theories of learning, practice and information literacy together, Annmaree Lloyd and Sanna Talja, eds. (Wagga Wagga: Centre for Information Studies, Charles Sturt University, 2010), 4-27.

${ }^{14}$ Eamon Tewell, "A decade of critical information literacy: A review of the literature", Communications in Information Literacy 9, no. 1 (2015): 2.

${ }^{15}$ Clarence Maybee, IMPACT Learning: Librarians at the Forefront of Change in Higher Education. (Oxford: Chandos Publishing, 2018).

${ }^{16}$ Lisa O'Connor, "Information literacy as professional legitimation: The quest for professional jurisdiction", Library Review, 58, no. 4 (2009): 272-289.
} 


\section{Argumentacijska polazišta i obilježja kritičke informacijske pismenosti}

Danas sa sigurnošću možemo utvrditi da je kritička informacijska pismenost postala značajno i prepoznato područje istraživanja koje nudi alternativnu paradigmu, tj. „leću“ za ispitivanje i tumačenje informacijske pismenosti. ${ }^{17}$ Međutim, ovu alternativnu paradigmu nije lako teorijski opisati i precizirati, unatoč sve većem broju znanstvenih radova, ${ }^{18}$ inicijativa ${ }^{19} \mathrm{i}$ primjera dobre prakse. ${ }^{20}$

Autor kojeg možemo smatrati ključnim za teorijsko određenje kritičke informacijske pismenosti, čiji je rad i bibliometrijski identificiran kao najcitiraniji21 je James Elmborg, koji je 2006. godine objavio članak pod nazivom "Kritička informacijska pismenost: implikacije za nastavnu praksu". ${ }^{22} \mathrm{U}$ svom radu Elmborg tvrdi da se kritička informacijska pismenost može utemeljiti u kritičkim pedagogijama Pabla Freira, Henry Girouxa i brojnih drugih čiji su radovi fokusirani na osnaživanje osoba koje uče u svrhu prevladavanja opresivnih društvenih ili obrazovnih struktura. Prema Freireu, zapadnjačko obrazovanje vođeno je ideologijom kapitalizma koje učenika priprema za rad na radnom mjestu, umjesto da razvija kritičku svijest. To podrazumijeva napuštanje pristupa u kojem se skupljaju znanja i omogućavanje da osobe koje uče prepoznaju i da se suoče sa relevantnim problemima u svijetu. Knjižnica ne može biti u službi pasivizacije, već na temelju demokratskih principa mora sudjelovati u produbljivanju kritičke svijesti, a informacijska pismenost u tom smislu uključuje razumijevanje cijelog sustava mišljenja i toka informacija u tom sustavu, kao i sposobnost njegove kritičke evaluacije. ${ }^{23}$

Opisujući razlike između tradicionalnih i kritičkih pristupa informacijskoj pismenosti Riddle navodi da u kritičkoj informacijskoj pismenosti znanje i informacije nisu objektivni i eksternalizirani u zbirkama knjiga ili bazama podataka, već kulturno posredovani, društveno konstruirani, fragmentirani i ne-linearni entiteti. ${ }^{24}$ Zbog toga je posrijedi obrazovna perspektiva koja nije fokusirana na stjecanje vještina, već potiče kritični i diskurzivni pristup informacijama. lako se kritička informacijska pismenost i dalje bavi pitanjima pristupa informacijama i njihovog pronalaženja i stvaranjem znanja, istovremeno postavlja pitanja o tome zašto neke informacije dominiraju dok su druge marginalizirane, te problematizira proizvodnju informacija kako bi se korisnike potaklo na kritičko promišljanje tih procesa. Stoga Gregory i Higgins zaključuju kako se kritička informacijska pismenost bavi društveno osviještenim interakcijama s informacijama i razmatra društvene, političke, ekonomske i korporacijske sustave koji upravljaju proizvodnjom, diseminacijom, pristupom i potrošnjom informacija. ${ }^{25}$

Potreba za proširenjem dominantno funkcionalnih pristupa transformativnim i kritičnim pristupima dodatno proizilazi iz obilježja digitalnih informacijskih okruženja, koja su zasnovana na algoritmima koji diktiraju informacijsko iskustvo korisnika. Spomenuti algoritmi, koji oblikuju

\footnotetext{
${ }^{17}$ Heidi Jacobs, "Pedagogies of possibility within the disciplines: Critical information literacy and literatures in English", Communications in Information Literacy 8, no. 2 (2014): 194-195.

18 Usp. Gloria ). Leckie et al., Critical Theory for Library and Information Science Exploring the Social from across the Disciplines (Santa Barbara, Denver, Oxford: Libraries Unlimited, 2010); Maria T. Accardi et al., Critical Library Instruction Theories and Methods (Duluth, Minn: Library Juice Press, 2010).

${ }^{19}$ Npr. inicijativa Radical Librarians Collective, https://rlc.radicallibrarianship.org/ (preuzeto 3. 3. 2018).

${ }^{20} \mathrm{Na}$ primjer repozitorij primjera dobre prakse ACRL Framework for Information Literacy Sandbox, http://sandbox.acrl.org/ (preuzeto 4. 3. 2018).

${ }^{21}$ Denis Kos and Sonja Špiranec, "Understanding the Field of Critical Information Literacy: A Descriptive Analysis of Scientific Articles", in Information Literacy: Moving Toward Sustainability, Serap Kurbanoğlu et al., eds. (Heidelberg: Springer International Publishing, 2015).

22 James Elmborg, "Critical information literacy: Implications for instructional practice", The Journal of Academic Librarianship 32, no. 2 (2006): 192-199.

${ }^{23}$ Denis Kos, "Teorijske perspektive informacijske pismenosti: kritičko pedagogijski pogled“ (diplomski rad, Filozofski fakultet u Zagrebu, 2014), 31.

${ }^{24}$ John Riddle, "Information and service learning", in Critical Library Instruction Theories and Methods, Maria T. Accardi et al., eds. (Duluth, Minn: Library Juice Press, 2010), 136.

${ }^{25}$ Lua Gregory and Shana Higgins, Information Literacy and Social Justice: radical professionl praxis (Sacramento: Library juice press, 2014), 4
} 
pogled u svijet informacija, programirani su prema nečijem interesu. Problematiziranje takve informacijske stvarnosti fokus je kritičke informacijske pismenosti. Manifestacije kritičkih pismenosti u digitalnim okruženjima razradile su Johannson i Limberg, ${ }^{26}$ uočavajući dvije razine kritičkih pristupa u praksi: a) razinu kritičkog vrednovanja i procjene te b) transformativnu razinu. Kao što je prethodno spomenuto, razina kritičkog vrednovanja izvora sastavni je dio mnogih postojećih modela digitalne ili informacijske pismenosti, pri čemu se nerijetko propisuju fiksirani kriteriji ili vještine procjene kvalitete, pouzdanosti ili primjerenosti izvora. No, u takvim koncepcijama osoba i dalje može biti pasivni primatelj sadržaja koji će prihvatiti, odbaciti ili kritizirati informacije koje su pronađene. Druga, transformativna razina zaoštrava kritički pristup angažiranim postupcima koji su usmjereni na kritiku, pa i transformaciju informacija, informacijskih procesa i struktura. Takav pristup podrazumijeva osnaživanje za transformativnu akciju koja propituje status quo i opire se prihvaćanju dominantnih struktura i mehanizama stvaranja i tijeka informacija digitalnim prostorima, što uključuje i aktivno djelovanje u stvaranju i komuniciranju informacija. Takva pismenost nužno je usmjerena na emancipaciju i osnaživanje za promjenu. Kritička misao se ne odnosi samo na pronađene sadržaje ili njihovu produkciju/komuniciranje, već na kritičko promišljanje o mogućnostima i izazovima digitalne tehnologije u svim njenim manifestacijama i oblicima.

Mnogi su autori istaknuli da u visokom obrazovanju postoji izrazita potreba zaokreta prema kritičkim pristupima, te su upravo fakultetski knjižničari aktivni predvodnici kritičke informacijske pismenosti. Pritom upućuju na kritičko propitivanje konteksta visokog obrazovanja koje sve više nalikuje korporacijskom sektoru ${ }^{27}$ i ekonomskog modela funkcioniranja znanstvene komunikacije. ${ }^{28}$ Svoj su praktični okvir djelovanja, koji uzima u obzir opisane točke potrebnog zaokreta u informacijskoj pismenosti, visokoškolski knjižničari dobili u dokumentu Okvir za informacijske pismenosti, ${ }^{29}$ koji je objavljen 2015. kao alternativa Standardima informacijske pismenosti koji su gotovo 15 godina bili slovili kao glavna referentna točka primjene i integracije informacijske pismenosti u visoko obrazovanje.

\section{Umjesto standarda: Novi okvir informacijske pismenosti u visokom obrazovanju}

Američko udruženje visokoškolskih i znanstvenih knjižnica (ACRL) 2015. godine usuglasilo je i objavilo dokument Okvir informacijske pismenosti u visokom obrazovanju kao novo polazište za teorijsko i praktično utemeljenje informacijske pismenosti u kontekstu visokog obrazovanja. lako se u uvodnom tekstu dokumenta ističe da su promjene u informacijskom ekosustavu, pri čemu se misli na promjene u tehnologiji, znanstvenoj komunikaciji i informacijskom ciklusu, potakle stvaranje novog okvira, dokument se jasno odredio prema neodrživosti pristupa informacijskom opismenjivanju na kojima se temelje Standardi informacijske pismenosti iz 2000. godine, jasno dajući do znanja da se novim okvirom želi postići odmak i zaokret u razumijevanju i praktičnoj primjeni informacijske pismenosti u visokom obrazovanju.

Okvir se sastoji od klastera 6 međusobno povezanih polazišnih koncepata koji su fleksibilni u implementaciji, za razliku od prijašnjih standarda s popisanim ishodima učenja; riječ je o sljedećim polazišnim konceptima:

\footnotetext{
${ }^{26}$ Veronica Johansson and Louise Limberg, "Seeking critical literacies in information practices: reconceptualising critical literacy as situated and tool-mediated enactments of meaning", Information Research 22, no. 1 (2017), http://www.informationr.net/ir/22-1/colis/ colis1611.html (preuzeto 15. 2. 2018).

${ }^{27}$ Cathy Eisenhower and Dolsy Smith, "The library as 'stuck place': Critical pedagogy in the corporate university", in Critical Library Instruction Theories and Methods, Maria T. Accardi et al., eds. (Duluth, Minn: Library Juice Press, 2010), 305-318.

${ }^{28}$ Stuart Lawson et al., "Commodification of the information profession: A critique of higher education under neoliberalism", Journal of Librarianship and Scholarly Communication 3, no. 1 (2015).

${ }^{29}$ ALA, Framework for Information Literacy for Higher Education (2015), http://www.ala.org/acrl/standards/ilframework (preuzeto 3. 3. 2018)
} 
- autoritet je konstruiran i kontekstualan (različitim zajednicama važan je drugačiji tip autoriteta, autoritet ovisi o informacijskoj potrebi),

- stvaranje informacija kao proces (proces istraživanja, stvaranja i diseminacije informacije iterativan je i varira, a rezultat odražava te razlike),

- informacija ima vrijednost (pravni i društvenoekonomski interesi utječu na stvaranje i diseminaciju informacija),

- istraživanje kao postavljanje pitanja (istraživanje je iterativno i ovisi o postavljanju sve kompleksnijih i novijih pitanja čiji odgovori generiraju nova pitanja),

- znanost kao konverzacija (zajednice znanstvenika i istraživača konstantno raspravljaju i nude nove uvide i otkrića koji su rezultat promjenjivih perspektiva i interpretacija),

- traženje kao strateško ispitivanje (traženje informacija često je nelinearno i iterativno, zahtijeva vrednovanje različitih izvora i mentalnu fleksibilnost za razvijanje novih pristupa).

Iz navedenog proizlazi da je filozofsko utemeljenje novog Okvira za informacijsku pismenosti bitno različito od ranijih Standarda iz 2000. Dok su Standardi pozitivistički postulirani, budući da informaciju tretiraju kao objektivni i mjerljiv entitet kojega student treba, prema propisanim procedurama i kriterijima pronaći, vrednovati i koristiti, Okvir za informacijsku pismenost je konstruktivistički intoniran jer polazi od pretpostavke da se znanje konstruira i re-konstruira društvenim interakcijama, što Okvir približava stajalištima kritičke informacijske pismenosti. Prema Foasbergu, Okvir za informacijsku pismenost sugerira da se informacije ne nalaze samo u informacijskim izvorima, već kao društveni fenomen nastaju u zajednicama, pa i informacijska pismenost ovisi o razumijevanju konteksta. ${ }^{30}$ Kontekst može mijenjati značenje određenih poruka i vrijednosti tih poruka, što omogućuje kritiku društvenih i institucionalnih hijerarhija koje proizvode i distribuiraju informacije, a ova je ideja ujedno u srži kritičke informacijske pismenosti.

Ako se teorijske i filozofske postavke kritičke informacijske pismenosti i Okvira za informacijsku pismenost projiciraju u praksi informacijskog opismenjivanja koje provode visokoškolski knjižničari, fokus edukacije korisnika proširit će se sadržajno i pedagoški te obuhvatiti teme koje će korisnike potaknuti na promišljanje i razumijevanje različitih struktura publiciranja, alternativnih metoda publiciranja, otvorenog pristupa, prava i mogućnosti izbora u odnosu na vlastita autorska prava, komercijalnih interesa u sustavima znanstvene komunikacije i općenito preusmjeriti informacijsku pismenost na učenje o prirodi informacija, a ne o informacijskim alatima kao što je to do sada bio slučaj.

\section{Zaključak}

Koncept kritičke informacijske pismenosti neprijeporno pruža jedinstven teorijski doprinos u suvremenim promišljanjima o informacijskoj pismenosti, a danas je taj „pravac“ postigao prepoznatljiv status u profesionalnoj zajednici knjižničara. Ovaj je rad imao za cilj analitički propitati koncept kritičke informacijske pismenost, pri čemu se nastojalo utvrditi u kojoj mjeri kritička informacijska pismenost pokušava pronaći rješenja za konceptualne dvojbe i probleme koji su se pojavili u diskursu tradicionalne i funkcionalno usmjerene informacijske pismenosti.

Mnogobrojne rasprave pokazale su da generički i funkcionalno usmjeren pristup temeljen na popisu vještina, koji je manifestiran u standardima, zanemaruje činjenicu da je svaka pismenost socio-kulturni konstrukt, ideološka praksa, ugniježđena u društveni, kulturni kontekst i nije usklađen sa suvremenim nelinearnim i dinamičnim informacijskim ekosustavom. Kritička

\footnotetext{
${ }^{30}$ Nancy M. Foasberg, "From standards to frameworks for IL: How the ACRL framework addresses critiques of the standards", Portal: Libraries and the Academy 15, no. 4 (2015): 703.
} 
informacijska pismenost usmjerena je upravo na ova problemska područja te stoga ne iznenađuje da su teorijske rasprave vrlo brzo urodile konkretnim rezultatom, Okvirom za informacijsku pismenost, koji je objavljen kao alternativa Standardima kako bi polučio zaokret u praksi informacijskog opismenjivanja u visokoškolskim institucijama. Prema polazištima kritičkih pristu$\mathrm{pa}$, svrha informacijske pismenosti u visokoškolskom kontekstu nije reducirana na stjecanje vještina i pripremu pojedinca za tržište rada, već na emancipaciju i osnaživanje pojedinca za promjenu kroz kritičko propitivanje brojnih političkih, ekonomskih ili komercijalnih interesa koji definiraju stvaranje, diseminaciju i korištenje informacija, pristup znanju, a time i razumijevanje svijeta.

\section{Literatura i izvori:}

1. Accardi, Maria T., Emily Drabinski and Alana Kumbier. Critical Library Instruction Theories and Methods. Duluth; Minn: Library Juice Press, 2010.

2. ACRL Framework for Information Literacy Sandbox. http://sandbox.acrl.org/ (preuzeto 4. 3. 2018).

3. ALA. Framework for Information Literacy for Higher Education. 2015. http://www.ala.org/acrl/standards/ ilframework (preuzeto 3. 3. 2018).

4. American Library Association. Presidential Committee on Information Literacy: Final Report. http://www. ala.org/acrl/publications/whitepapers/presidential (preuzeto 12. 2. 2018).

5. Association of College, Research Libraries and American Library Association. Information literacy competency standards for higher education. 2000. https://alair.ala.org/bitstream/handle/11213/7668/ ACRL\%20Information\%20Literacy\%20Competency\%20Standards\%20for\%20Higher\%20Education. pdf? sequence=1\&isAllowed $=y$ (preuzeto 22. 2. 2018).

6. Eisenhower, Cathy and Dolsy Smith. "The library as 'stuck place': Critical pedagogy in the corporate university". In Critical Library Instruction Theories and Methods. Maria T. Accardi, Emily Drabinski and Alana Kumbier, eds., 305-318. Duluth, Minn: Library Juice Press, 2010.

7. Elmborg, James. "Critical information literacy: Definitions and challenges". Transforming information literacy programs: Intersecting frontiers of self, library culture, and campus community 64 (2012): 75-80.

8. Elmborg, James. "Critical information literacy: Implications for instructional practice". The Journal of Academic Librarianship 32, no. 2 (2006): 192-199.

9. Foasberg, Nancy M. "From standards to frameworks for IL: How the ACRL framework addresses critiques of the standards". Portal: Libraries and the Academy 15, no. 4 (2015): 699-717.

10. Gregory, Lua and Shana Higgins. Information Literacy and Social Justice: radical professionl praxis. Sacramento: Library juice press, 2014.

11. Jacobs, Heidi. "Pedagogies of possibility within the disciplines: Critical information literacy and literatures in English". Communications in Information Literacy 8, no. 2 (2014): 192-207.

12. Johansson, Veronica and Louise Limberg. "Seeking critical literacies in information practices: reconceptualising critical literacy as situated and tool-mediated enactments of meaning". Information Research 22, no. 1 (2017). http://www.informationr.net/ir/22-1/colis/colis1611.html (preuzeto 15. 2. 2018).

13. Kapitzke, Cushla. "Information literacy: A positivist epistemology and a politics of outformation". Educational theory 53, no. 1 (2003): 37-53.

14. Kos, Denis and Sonja Špiranec. "Understanding the Field of Critical Information Literacy: A Descriptive Analysis of Scientific Articles". In Information Literacy: Moving Toward Sustainability. Serap Kurbanoğlu, Joumana Boustany, Sonja Špiranec, Esther Grassian, Diane Mizrachi and Loriene Roy, eds., 579-589. Heidelberg: Springer International Publishing, 2015.

15. Kos, Denis. "Teorijske perspektive informacijske pismenosti: kritičko pedagogijski pogled“. Diplomski rad, Filozofski fakultet u Zagrebu, 2014. 
Špiranec S. „Kritička informacijska pismenost u akademskom kontekstu“, 3-11

16. Lawson, Stuart, Kevin Sanders and Lauren Smith. "Commodification of the information profession: A critique of higher education under neoliberalism". Journal of Librarianship and Scholarly Communication 3, no. 1 (2015).

17. Leckie, Gloria J., Lisa M. Given and John Buschman. Critical Theory for Library and Information Science Exploring the Social from across the Disciplines. Santa Barbara; Denver; Oxford: Libraries Unlimited, 2010.

18. Lupton, Mandy and Christine Bruce. "Windows on information literacy worlds: Generic, situated and transformative perspectives". In Practising information literacy: Bringing theories of learning, practice and information literacy together. Annmaree Lloyd and Sanna Talja, eds., 4-27. Wagga Wagga: Centre for Information Studies, Charles Sturt University, 2010.

19. Marcum, James W. "Rethinking information literacy". The Library Quarterly 72, no. 1 (2002): 1-26.

20. Maybee, Clarence. IMPACT Learning: Librarians at the Forefront of Change in Higher Education. Oxford: Chandos Publishing, 2018.

21. O'Connor, Lisa. "Information literacy as professional legitimation: The quest for professional jurisdiction". Library Review 58, no. 4 (2009): 272-289.

22. Owusu-Ansah, Edward K. "Debating definitions of information literacy: enough is enough!". Library Review 54, no. 6 (2005): 366-374.

23. Radical Librarians Collective. https://rlc.radicallibrarianship.org/ (preuzeto 3. 3. 2018).

24. Riddle, John. "Information and service learning". In Critical Library Instruction Theories and Methods. Maria T. Accardi, Emily Drabinski and Alana Kumbier, eds., 133-148. Duluth, Minn: Library Juice Press, 2010.

25. Seale, Maura. "The neoliberal library". In Information literacy and social justice: Radical professional praxis. Lua Gregory and Shana Higgins, eds, 39-61. Sacramento: Library juice press, 2014.

26. Shapiro, Jeremy J. i Shelley K. Hughes. "Information literacy as a liberal art?". Educom review 31 (1996): 31-35.

27. Snavely, Loanne i Natasha Cooper. "The information literacy debate". The Journal of Academic Librarianship 23, no. 1 (1997): 9-14.

28. Tewell, Eamon. "A decade of critical information literacy: A review of the literature". Communications in Information Literacy 9, no. 1 (2015): 24-43.

29. UNESCO. Alexandria Proclamation on Information Literacy and Lifelong Learning. http://www.unesco. org/new/en/communication-and-information/resources/news-and-in-focus-articles/all-news/news/ alexandria_proclamation_on_information_literacy_and_lifelong/. (preuzeto 22. 2. 2018).

30. Webber, Sheila i Bill Johnston. "Conceptions of information literacy: new perspectives and implications". Journal of information science 26, no. 6 (2000): 381-397.

31. Whitworth, Andrew. Radical information literacy: Reclaiming the political heart of the IL movement. Oxford: Chandos, 2014.

32. Zurkowski, Paul G. The Information Service Environment Relationships and Priorities, Related Paper No. 5. Washington D.C: National Commission on Libraries and Information Science, 1974. https://eric. ed.gov/?id=ED100391 (preuzeto 27. 2. 2018). 


\title{
Critical Information Literacy in the Academic Context
}

\begin{abstract}
Although there is a wide consensus on theoretical concepts and the pragmatic focus of IL, specifically in academic librarianship, many initial premises in the field have lately been discussed and questioned. The re-examination of wide-held assumptions in information literacy, the critique of its proclaimed purpose and practical manifestations led to the shift towards critical information literacy.

The aim of this paper is to determine whether critical information literacy provides a distinctive theoretical contribution to the contemporary discourse in information literacy. Based on qualitative literature analysis the authors will examine some basic ideas and conceptual assumptions of critical information literacy and contrast and compare the dominant instrumentally-focused approach to information literacy with critical approaches. Specifically, the authors will try to determine to what extent core concepts of critical information literacy reflect on questions, dilemmas and problems identified in information literacy theory and praxis in the last decades, and whether critical information literacy offers a viable framework for perceived weaknesses, with an explicit outlook to the context of higher education.
\end{abstract}

Keywords: critical information literacy, higher education, standards, Framework in information literacy in higher education, workplace, skills-based approach 
